\title{
Lifted temperature minimum during the atmospheric evening transition
}

\author{
E. Blay-Carreras ${ }^{1}$, E. R. Pardyjak ${ }^{2}$, D. Pino ${ }^{1,3}$, S. W. Hoch ${ }^{4}$, J. Cuxart ${ }^{5}$, D. Martínez ${ }^{6}$, and J. Reuder \\ ${ }^{1}$ Department of Applied Physics, Universitat Politècnica de Catalunya, BarcelonaTech, Barcelona, Spain \\ ${ }^{2}$ Department of Mechanical Engineering, University of Utah, Salt Lake City, UT, USA \\ ${ }^{3}$ Institute for Space Studies of Catalonia (IEEC-UPC), Barcelona, Spain \\ ${ }^{4}$ Department of Atmospheric Sciences, University of Utah, Salt Lake City, UT, USA \\ ${ }^{5}$ Grup de Meteorologia, Departament de Física, Universitat de les Illes Balears, Palma de Mallorca, Spain \\ ${ }^{6}$ Center for Applied Geoscience, University of Tübingen, Tübingen, Germany \\ ${ }^{7}$ Geophysical Institute, University of Bergen, Bergen, Norway \\ Correspondence to: E. Blay-Carreras (estel.blay@upc.edu)
}

Received: 18 July 2014 - Published in Atmos. Chem. Phys. Discuss.: 7 November 2014

Revised: 26 February 2015 - Accepted: 27 February 2015 - Published: 29 June 2015

\begin{abstract}
Observations of lifted temperature minimum (LTM) profiles in the nocturnal boundary layer were first reported in 1932. It was defined by the existence of a temperature minimum some centimetres above the ground. During the following decades, several research studies analysed this phenomenon verifying its existence and postulating different hypotheses about its origin.

The aim of this work is to study the existence and characteristics of LTM during the evening transition by using observations obtained during the Boundary Layer Late Afternoon and Sunset Turbulence (BLLAST) campaign. Data obtained from two masts instrumented with thermocouples and wind sensors at different heights close to the ground and a mast with radiometers are used to study the role of mechanical turbulence and radiation in LTM development.

The study shows that LTM can be detected under calm conditions during the day-night transition, several hours earlier than reported in previous work. These conditions are fulfilled under weak synoptic forcing when the local flow shifts associated with a mountain-plain circulation in relatively complex orography. Under these special conditions, turbulence becomes a crucial parameter in determining the ideal conditions for observing LTM. Additionally, LTM observed profiles are also related to a change in the atmospheric radiative characteristics under calm conditions.
\end{abstract}

\section{Introduction}

A lifted temperature minimum (LTM) profile is characterized by an elevated temperature minimum close to the surface. Depending on the ground characteristics, LTM is typically located between 10 and $50 \mathrm{~cm}$ above the surface and observed at night. After sunset, if cloudless and calm conditions exist and ground and air emissivities have similar values, the air layer just above the ground can cool radiatively faster than the ground itself and a minimum temperature appears several centimetres above the surface. LTMs have been studied by means of observations (Ramdas and Atmanathan, 1932; Lake, 1956; Raschke and Atmanathan, 1957; Oke, 1970), numerical simulations (Zdunkowski, 1966; Vasudeva Murthy et al., 1993; Narasimha and Vasudeva Murthy, 1995; Vasudeva Murthy et al., 2005) and laboratory experiments (Mukund et al., 2010, 2014).

Ramdas and Atmanathan (1932) provided for the first time a detailed description of the unexpected temperature minimum neglecting advective effects, and suggested that the LTM might be related with radiation from the ground and the lower layer of the atmosphere. Several years later, Lake (1956), and Raschke and Atmanathan (1957) confirmed the results obtained by Ramdas and Atmanathan (1932), discarding instrumental errors by using more complex instruments. Raschke and Atmanathan (1957) took measurements over different terrain types to verify that LTMs are not produced 
by advection and defined three different types of temperature profiles, distinguishing between profiles with the minimum temperature at the ground and LTM profiles caused by advection. Additionally, they made measurements at different latitudes to prove that the phenomenon was not restricted to the tropics. On the contrary, Geiger (1965) showed some skepticism about the existence of LTM. For instance, he wondered why LTMs are not overturned by convective instability. He was also concerned about the precision of the measurements close to the ground. Later on, Zdunkowski (1966) suggested the existence of a haze layer near the ground to explain the appearance of the LTM. Nevertheless, this approach was discarded because this layer was never observed and the thermal diffusivity required for its explanation was not realistic (Narasimha, 1994).

More recent studies have shown that LTM observations are common over different natural, e.g. bare soil, snow and short grass (Oke, 1970) and artificial surfaces such as concrete or thermofoam (Mukund et al., 2010, 2014). Mukund et al. (2014) studied in detail the importance of surface characteristics for the appearance of LTM. They demonstrated, by studying LTM formation over different surfaces (aluminum, thermofoam and concrete), that decreasing surface emissivity increases the intensity of an LTM and the near-ground temperature gradient. Lowering surface emissivity with respect the overlying atmosphere can act to change the temperature profile from a minimum temperature occurring at the ground to an elevated temperature minimum. Therefore, terrain with an emissivity close to that of the overlying air favours LTM formation. Narasimha $(1991,1994)$ summarized the main mechanisms related to the occurrence of LTM. In his first summary, he introduced a brief description of a model, which was later described in detail in Vasudeva Murthy et al. (1993). They hypothesized that radiative cooling depends on ground emissivity and air emissivity gradient. When the air emissivity gradient is large, the temperature of the air close to the ground decreases faster than the temperature of the ground and an LTM can be observed. Even though the model presented a detailed solution for the air temperature evolution considering surface emissivity, ground cooling and turbulence, it did not include a detailed discussion of the energy budget near the ground, which was introduced afterwards by Narasimha and Vasudeva Murthy (1995).

Apart from ground thermal characteristics, calm conditions with low mechanical turbulence are crucial to observe an LTM. For instance, LTM intensity is weaker for high roughness length surfaces because it increases both turbulence and emissivity (Oke, 1970). Moreover, field measurements (Ramdas and Atmanathan, 1932; Lake, 1956; Raschke and Atmanathan, 1957; Oke, 1970) and models (Vasudeva Murthy et al., 1993; Narasimha and Vasudeva Murthy, 1995; Vasudeva Murthy et al., 2005) show that advection was weak when an LTM was observed. The LTM has only been reported for a small number of cases where the friction veloc- ities were above $0.1 \mathrm{~m} \mathrm{~s}^{-1}$, and in those cases LTM disappeared relatively quickly (Vasudeva Murthy et al., 2005).

Vasudeva Murthy et al. (1993) were the first to suggest a model which appears to be in good agreement with observations. They studied the importance of radiative, conductive and convective fluxes during LTM events. This model was accepted until Mukund et al. (2010) and Ponnulakshmi et al. (2012) identified an error in the calculations of Vasudeva Murthy et al. (1993) and introduced a new model based on the work by Edwards (2009a). This model includes the importance of suspended solid or liquid particles, which can enhance radiative cooling. Narasimha (1991), Vasudeva Murthy et al. (2005), and Mukund et al. (2010, 2014) pointed out the importance of radiation in the formation of LTM. Mukund et al. (2010) confirmed that near the surface, radiative cooling can be orders of magnitude greater than values elsewhere in the boundary layer. With very light winds, the importance of turbulence is nearly negligible compared with radiation. Therefore, temperature evolution is mainly governed by the radiative timescale (Vasudeva Murthy et al., 2005). Moreover, Mukund et al. (2014) showed that a heterogenous distribution of aerosol concentration can cause hyper-cooling close to the surface, which modifies the atmospheric radiative cooling.

Another hypothesis explaining the appearance of LTM (or the temperature maximum at upper levels, around $20-30 \mathrm{~cm}$ ) during the night in stable conditions is based on the competition between the radiative warming of the lower layers (up to 50-70 cm) of the atmosphere, over a rapidly cooling surface, and the turbulence cooling (Savijarvi, 2006, 2014; Edwards, 2009a, b). The first process would drive the heat budget at $20-30 \mathrm{~cm}$, but turbulence cooling would temporarily be dominant around $10-15 \mathrm{~cm}$.

Finally, daytime LTM measurements have been reported when near-surface temperature inversions occur under specific conditions over the open Arabian Sea during the summer monsoon season (Bhat, 2006). These atmospheric conditions, characterized by strong surface winds and high levels of sea salt particle concentration in the boundary layer, are far away from the conditions presented at night or here.

In summary, LTM occurrence varies depending on surface characteristics (emissivity and thermal inertia), prevailing wind conditions (turbulence) and atmospheric radiation. In contrast with previous studies, we analyse LTM occurrences during the evening transition period. It is during this period when the largest radiative cooling occurs (Sun et al., 2003). Our research objective is to study the relevance of wind characteristics driven by orography, turbulence, characterized by the Richardson number and radiation on the appearance of LTM during the evening transition.

The study of the appearance of LTM, besides increasing the knowledge of the physics of the surface layer, can also be relevant for agriculture. The lifted temperature minimum can modify the occurrence of frost, which has adverse effects on crops (Lake, 1956). Moreover, it can help to describe the 
presence of radiation fog because, as it will be shown, the presence of LTM is related with a variation of the radiation (Mukund et al., 2014).

The paper is structured as follows. In Sect. 2 we explain the measurements used in this study, taken during the Boundary Layer Late Afternoon and Sunset Turbulence (BLLAST) campaign. In Sect. 3, the temperature profiles are analysed in detail and LTM characteristics are described. Section 4 investigates and presents the variables influencing LTM: wind characteristics and friction velocity, turbulence and radiation. Finally, Sect. 5 summarizes the results.

\section{Measurements}

To investigate LTM during the evening transition, we analyse measurements acquired during the BLLAST field experiment (Lothon et al., 2014). This campaign was performed from 14 June to 8 July 2011 in southern France, near to the Pyrenees. The campaign site extended over an area of approximately $100 \mathrm{~km}^{2}$ covered with heterogeneous vegetation: mainly grass, corn, moor and forest.

The most salient BLLAST objective was to obtain a detailed set of meteorological observations during the evening transition to better understand the physical processes that control it. For example, to improve the understanding of the effects of entrainment across the boundary layer top, surface heterogeneity, horizontal advection, clouds, radiation and gravity waves on the evening transition.

During intensive observational periods (IOPs), the atmosphere was heavily probed by in situ measurements from masts, towers, tethered balloons, radiosondes and manned and unmanned airplanes, as well as remote sensing instruments such as lidar and radar wind profilers.

For the present work, the near surface temperature evolution is analysed using the measurements taken at two masts (T1 and T2) separated by approximately $468 \mathrm{~m}$. Figure 1 shows a plan view of the T2 area and a side view of the T1 and T2 instruments. T1 was located at $43.1275^{\circ} \mathrm{N}$, $0.36583^{\circ} \mathrm{E}$ and $\mathrm{T} 2$ at $43.1238^{\circ} \mathrm{N}, 0.36416^{\circ} \mathrm{E}$. T1 was a $10 \mathrm{~m}$ mast instrumented with four Campbell Scientific CSAT3 sonic anemometer thermometers and Campbell Scientific ETYPE model FW05 (12.7 $\mu$ m diameter) fine wire (FW) thermocouples at 2.23, 3.23, 5.2 and $8.2 \mathrm{~m}$. Closer to the ground, there were four additional FW05 $12.7 \mu \mathrm{m} \mathrm{FWs} \mathrm{at} \mathrm{0.091,}$ $0.131,0.191$ and $0.569 \mathrm{~m}$, which were only installed during the IOPs. Temperature data at T1 were recorded at $20 \mathrm{~Hz}$. The influence of direct or indirect solar radiation has been taken into account in the measurements. Moreover, Campbell (1969) showed that as the size of the thermocouple goes down, the radiative influence is reduced. For a $25 \mu \mathrm{m}$ sensor a $0.1 \mathrm{~K}$ of error was observed. Our sensor is half that size; hence, the error of the instrument should be lower than $0.1 \mathrm{~K}$, which is smaller than the values of the LTM intensity.
T2 was a $2 \mathrm{~m}$ mast with eight FW3 (76.2 $\mu \mathrm{m}$ diameter) FWs located at $0.015,0.045,0.075,0.14,0.3,0.515,1.045$ and $1.92 \mathrm{~m}$ recording temperature data at $10 \mathrm{~Hz}$. Additionally, separated by approximately $2 \mathrm{~m}$ from T2, there was also a Campbell Scientific CSAT3 at $1.95 \mathrm{~m}$, recording data at $20 \mathrm{~Hz}$. To unify the measurements taken by the different instruments, all the recorded data were averaged over $5 \mathrm{~min}$ intervals (De Coster and Pietersen, 2011). This information was complemented with an estimation of the skin temperature provided by a Campbell Scientific IR120 infrared remote temperature sensor pointing towards the surface. This infrared sensor measured temperature with a sampling frequency of $3 \mathrm{~Hz}$ before 21 June 2011 and of $1 \mathrm{~Hz}$ after this day.

Near T2, one Kipp \& Zonen CNR1 net radiometer was installed. The CNR1 sensor is able to measure upwelling and downwelling components of both the shortwave solar $(0.305-2.8 \mu \mathrm{m})$ and terrestrial radiation $(5-50 \mu \mathrm{m})$ separately. The CNR1 was installed at $0.8 \mathrm{~m}$ above the ground.

The ground characteristics below both masts were conducive to observe LTM (Mukund et al., 2014). The ground in both cases was covered by long grass, which has an emissivity of 0.986 (Gayevsky, 1952). The vegetation cover has low thermal conductivities which vary from 0.05 to $0.46 \mathrm{~W} \mathrm{~m}^{-1} \mathrm{~K}^{-1}$ (Campbell and Norman, 1998). However, the surface surrounding T1 was covered by long grass while the T2 surface had some cut grass over the terrain, which could cause some heterogeneity in the surface thermal properties.

Oke (1970) pointed out that, over grass-covered surfaces, the minimum temperature during the night can be found just above the grass instead of right at the surface. This phenomenon, which is associated with the vegetative canopy, is sometimes confused with an LTM. Oke (1970) observed an LTM at $0.02 \mathrm{~m}$ above the grass. In our case study, the grass height is short, around $0.03-0.07 \mathrm{~m}$, and the observed LTM height occurred above $0.1 \mathrm{~m}$ from the ground, that is, always above the grass.

For the following analysis, we selected different favourable IOPs with good data availability from the $\mathrm{T} 1$ and $\mathrm{T} 2$ areas. The analysis is based on the observations taken on 24, 25, 27, and 30 June and 1 and 2 July 2011. During these IOPs, we have measurements from both towers, the infrared surface temperature sensor and the radiometer. Almost all these IOPs were clear and calm days with a mountain-plain circulation characterized by weak northerly winds during the day switching to southerly at night. The synoptic situation did not show any notable perturbation.

\section{Observed LTM characteristics}

During the BLLAST campaign, when LTM occurred it was observed at both masts. Figure 2 shows the evolution of potential temperature profiles where an LTM is observed on 

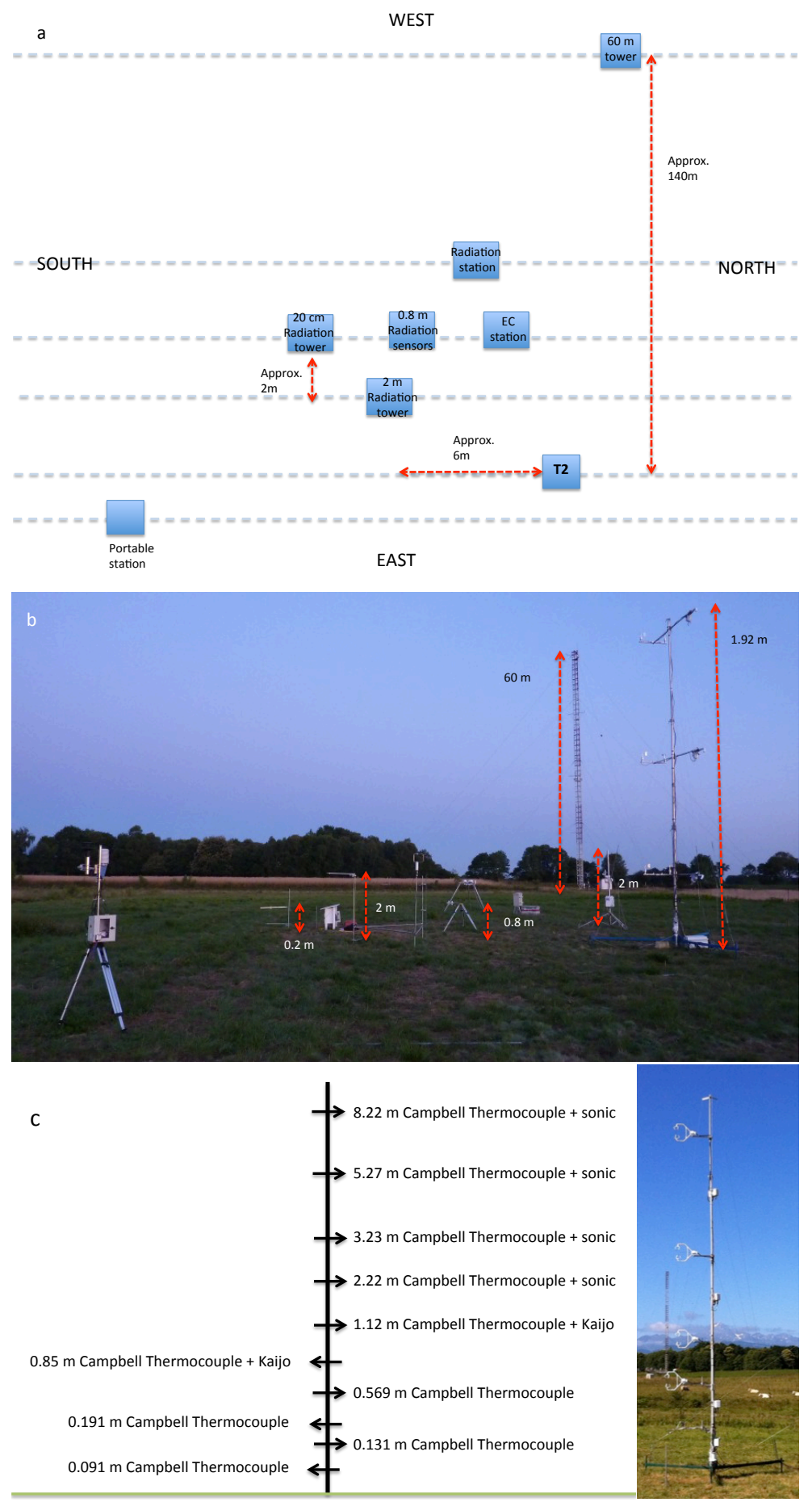

Figure 1. (a) Schematic horizontal view illustrating the location of the instrumentation around T2, (b) photograph (looking west) showing the instruments around $\mathrm{T} 2$, and (c) photograph (looking south) showing the instruments around the T1 mast. 

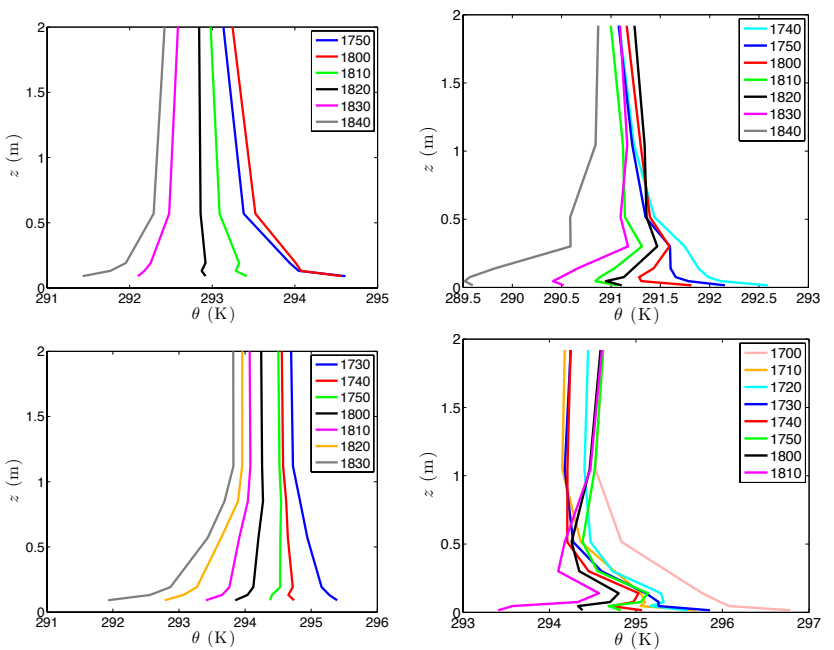

Figure 2. Temporal evolution of vertical potential temperature profiles with an observed LTM on 24 June 2011 (top) and 1 July 2011 (bottom) measured at T1 (left) and T2 (right).

24 June 2011 (top panels) and 1 July 2011 (bottom panels) recorded at T1 (left) and T2 (right). The LTM can be observed on both days at both masts.

As illustrated in Fig. 3, three sensors on each tower were used to detect and characterize LTM. First, the location of the minimum temperature was identified $\left(\theta_{\text {base }}\right)$. Next, the sensor closest to the ground was defined as LTM $\mathbf{v}$. Finally, the sensor located just above the base sensor (LTMム) was identified. An LTM is observed if

$\theta_{\text {base }}-\theta_{\text {LTM }}<0$ and $\theta_{\text {LTM }}-\theta_{\text {base }}>0$.

During this period, LTM intensity is calculated following (Mukund et al., 2010):

$\mathrm{LTM}_{\text {intensity }}=\theta_{\text {base }}-\theta_{\text {LTM } \mathbf{~}}$.

The LTM duration was defined as the period when the LTM conditions outlined above were fulfilled. Table 1 presents a summary of the following LTM characteristics for the different IOPs: height, intensity absolute values and duration of the phenomenon.

An LTM was observed during the evening transition for all IOP days except on 27 June 2011. An LTM forms at similar heights on both towers. For example, at T1 a height of around $0.131 \mathrm{~m}$ was typical, while LTM heights were between 0.075 and $0.14 \mathrm{~m}$ (except on 25 June 2011) at T2. Unfortunately, limitations in the vertical resolution of the measurements prevent a more precise determination of the LTM heights. In spite of this consistency, there are clear differences between the detailed LTM characteristics on different IOPs and at the different towers. On 24 June 2011, an LTM was observed during $10 \mathrm{~min}$ at $\mathrm{T} 1$ and for $40 \mathrm{~min}$ at T2. Greater LTM intensity $(0.7 \mathrm{~K})$ was observed at $\mathrm{T} 2$ compared to $\mathrm{T} 1(0.35 \mathrm{~K})$. On 25 June 2011, an LTM was detected at T2 at a slightly higher

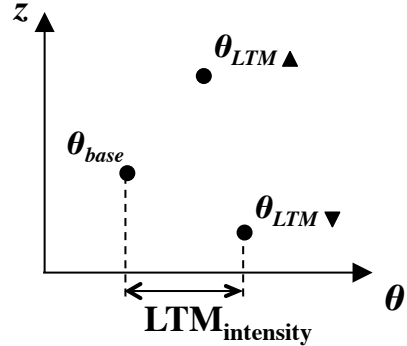

Figure 3. Illustration of the methodology used to identify LTM and quantify its intensity.

level, around $0.3 \mathrm{~m}$ with an intensity of $0.5 \mathrm{~K}$. This height is in the range of LTM heights reported by Raschke and Atmanathan (1957). On 25 June 2011, FWs were installed at T1 after 19:30 UTC (universal time coordinated); therefore, LTM comparisons cannot be made.

A completely different situation was observed on 27 June 2011; with no clear LTM development. T2 measurements showed indications of an LTM formation which did not progress (not shown).

On 30 June 2011, T1 showed a slightly lower-intensity (0.3 K) LTM starting around 18:00 UTC and lasting less than $20 \mathrm{~min}$. A slightly lower-intensity LTM was also observed at T2 with an intensity of $0.5 \mathrm{~K}$. On 1 July 2011 a clearly marked $(0.7 \mathrm{~K})$ LTM was observed at T2 during $1 \mathrm{~h}$. On the other hand, T1 showed a less pronounced LTM $(0.35 \mathrm{~K})$, which persisted only $20 \mathrm{~min}$. Finally, on 2 July 2011 T2 showed an LTM intensity of around $0.5 \mathrm{~K}$ with a duration of more than $1 \mathrm{~h}$. However, T1 showed an intensity of $0.35 \mathrm{~K}$ with a duration of $40 \mathrm{~min}$.

Due to the variations in sensor heights at the two locations, the LTM intensity can vary from one tower to the other. Day to day variations at a single location, however, can be compared. Specifically, our definition of LTM intensity is based on the temperature measured closest to the ground which, in order to detect an LTM, needs to be warmer than the LTM. The elevation of the sensor closest to the ground differs for $\mathrm{T} 1$ and $\mathrm{T} 2$ (about 9 and $1.5 \mathrm{~cm}$, respectively); thus, the two locations' intensities are not strictly comparable. As shown in Table 1, the LTM intensity at T2 is always roughly twice the value observed at $\mathrm{T} 1$, which is most likely due to the fact that the lowest thermocouple at $\mathrm{T} 1$ is still influenced by the cold air associated with the LTM and an additional increase in temperature towards the surface is not resolved.

\section{Variables influencing LTM development}

\subsection{Mean wind characteristics}

The analysis of wind conditions is crucial for understanding the influence of mechanical turbulence on the formation of LTM. Since during all of the IOPs presented in the analysis weak synoptic forcing occurred, orography will be the main 
Table 1. Characteristics of the LTM at T1 and T2 for all the studied IOPs.

\begin{tabular}{llllllll}
\hline IOP & LTM & $\begin{array}{l}\text { LTM height } \\
\text { T1 }(\mathrm{m})\end{array}$ & $\begin{array}{l}\text { LTM height } \\
\mathrm{T} 2(\mathrm{~m})\end{array}$ & $\begin{array}{l}\text { LTM intensity } \\
\text { T1 }(\mathrm{K})\end{array}$ & $\begin{array}{l}\text { LTM intensity } \\
\mathrm{T} 2(\mathrm{~K})\end{array}$ & $\begin{array}{l}\text { LTM duration } \\
\text { T1 }(\mathrm{min})\end{array}$ & $\begin{array}{l}\text { LTM duration } \\
\text { T2 }(\mathrm{min})\end{array}$ \\
\hline 24 June 2011 & Yes & 0.131 & $0.07-0.14$ & 0.35 & 0.7 & $18: 15-18: 25$ & $17: 50-18: 50$ \\
25 June 2011 & Yes & 0.131 & 0.3 & - & 0.5 & - & $17: 50-18: 20$ \\
27 June 2011 & No & - & - & - & - & - & $17: 55-18: 15$ \\
30 June 2011 & Yes & 0.131 & $0.07-0.14$ & 0.3 & 0.5 & $17: 55-18: 15$ \\
1 July 2011 & Yes & 0.131 & $0.07-0.14$ & 0.35 & 0.7 & $17: 35-18: 05$ & $17: 10-18: 10$ \\
2 July 2011 & Yes & 0.131 & $0.07-0.14$ & 0.3 & 0.5 & $17: 30-18: 20$ \\
\hline
\end{tabular}

driving mechanism of surface winds during the evening transition (Nadeau et al., 2013).

Figure 4 shows the temporal evolution of the averaged $2 \mathrm{~m}$ wind speed and direction every $5 \mathrm{~min}$ observed at $\mathrm{T} 1$ and T2. The observed wind directions shown in Fig. $4 a$ and $b$ clearly indicate for most of the days a typical mountainplain circulation (Whiteman, 2000): daytime plain-mountain wind (northerly over the Lannemezan Plateau toward the Pyrenees), early evening calm conditions and nighttime mountain-plain wind (southerly). The wind speed observations (see Fig. 4c, d) indicate slightly weaker winds at T2, most likely due to the presence of trees near to T2 and to the difference in the surface cover. Before 17:30 UTC, 2.5 and $2 \mathrm{~ms}^{-1}$ wind speeds were observed at $\mathrm{T} 1$ and $\mathrm{T} 2$, respectively. At 17:30 UTC, the wind speed started to decrease except on 27 June 2011, indicating the beginning of the evening calm period. However, the decrease rate was not the same for all the IOPs, being faster on 24 June and 1 and 2 July 2011. The wind speed continued decreasing until 18:30-19:00 UTC when the wind was around $0.5 \mathrm{~m} \mathrm{~s}^{-1}$ at both masts. During this period, the wind direction turned from northerly to southerly progressively (see Fig. 4a, b). After 19:00 UTC, surface flows from the mountains dominated, with increasing wind speed (see Fig. 4c, d).

In order to analyse why the wind-speed decay during the evening was different for the analysed days, a WRFmesoscale simulation (Skamarock et al., 2008) was performed with $3 \mathrm{~km}$ horizontal resolution from 29 June at 00:00 UTC until 3 July 2011 at 00:00 UTC. When analysing the atmospheric conditions at low levels during the evening, a surface northerly wind is simulated at Lannemezan $\left(43^{\circ} 12^{\prime} \mathrm{N}, 0.39^{\circ} \mathrm{E}\right)$ during the 3 days. However, on 30 June 2011 this northerly wind is simulated until a later hour than on 1 and 2 July 2011. This is due to the lower temperatures simulated in the Pyrenees mountain range on 30 June 2011 (not shown). A similar reason could explain the lowest wind decrease observed on 25 June 2011.

In stable conditions, Oke (1970) postulated that the wind speed at $0.25 \mathrm{~m}$ must be less than $0.4 \mathrm{~ms}^{-1}$ to observe an LTM over short grass. In our study case, sensors measuring wind speed were located at $2 \mathrm{~m}$. Therefore, we need to extrapolate this value to $0.25 \mathrm{~m}$ to be able to compare with previous results. To do this a log-law approximation for neu-
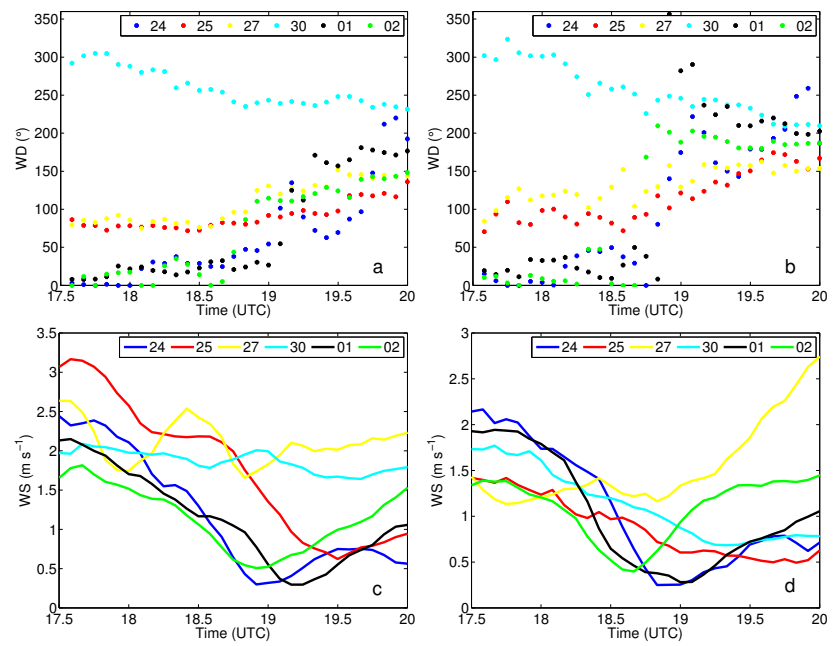

Figure 4. Temporal evolution, from 17:30 to 20:00 UTC, on all the studied days of the observed $2 \mathrm{~m}$ wind direction (top) and speed (bottom) averaged every $5 \mathrm{~min}$ at $\mathrm{T} 1$ (left) at $2.3 \mathrm{~m}$ and T2 (right) at $2 \mathrm{~m}$.

tral stability conditions was utilized, namely

$v \approx v_{\text {ref }} \frac{\ln \left(z / z_{0}\right)}{\ln \left(z_{\text {ref }} / z_{0}\right)}$,

where $v$ is the wind speed at height $z, v_{\text {ref }}$ is the wind speed at height $z_{\text {ref }}=2 \mathrm{~m}$, and $z_{0}$ is the roughness length $(0.03 \mathrm{~m}$ in our case). The results from this approximation show that for all the analysed days except 27 June 2011, the wind speed at $0.25 \mathrm{~m}$ is below $0.4 \mathrm{~m} \mathrm{~s}^{-1}$.

\subsection{Turbulence}

The gradient Richardson number $\left(R i_{\mathrm{g}}\right)$ is a crucial parameter in the study of the LTM during stable night conditions. Oke (1970) observed that $R i_{\mathrm{g}}>0.1$ is needed to observe an LTM over different terrain in stable conditions. The gradient for the Richardson number is defined as (Stull, 1988)

$R i_{\mathrm{g}}=\frac{g}{\overline{\theta_{\mathrm{v}}}} \frac{\partial \overline{\theta_{\mathrm{v}}} / \partial z}{(\partial U / \partial z)^{2}+(\partial V / \partial z)^{2}}$,

where $g$ is the gravity acceleration, $\overline{\theta_{\mathrm{v}}}$ is the virtual potential temperature, and $U, V$ the horizontal wind components. 


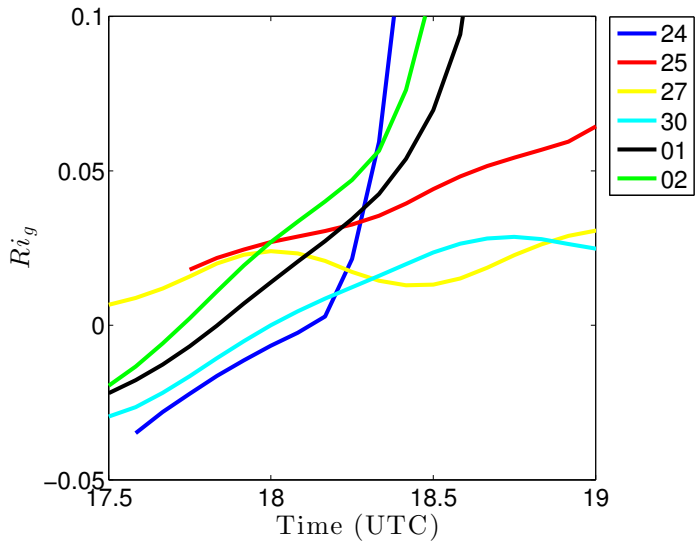

Figure 5. Temporal evolution of the Richardson number from 17:30 to 19:00 UTC on all the studied days at T1.

To estimate $R i_{\mathrm{g}}$, the potential temperature vertical gradient was computed using the $\theta_{\text {LTM }} \boldsymbol{\Lambda}$ and $\theta_{\text {base }}$ as, by definition, it is not possible to observe an LTM unless the $\partial \overline{\theta_{\mathrm{v}}} / \partial z$ is positive directly above the height where the LTM is observed. Moreover, as we do not have measurements of the wind speed at the LTM height or at LTM $\mathbf{\Delta}$, we approximate $U$ and $V$ using Eq. (3). Figure 5 shows the temporal evolution of $R i_{\mathrm{g}}$ during the evening transition obtained by using the data measured at $\mathrm{T} 1$ on all the studied days. As expected, as the stable surface layer develops, $R i_{\mathrm{g}}$ significantly increased for all the days studied except for 27 June 2011, when $R i_{\mathrm{g}}$ remains nearly constant and close to zero. During this day, an LTM was not observed because large mechanical turbulence in the lower part of the boundary layer existed.

An opposite situation occurred on 24 June and 1 and 2 July 2011. On these days a large increase of the $R i_{\mathrm{g}}$ values is observed when $R i_{\mathrm{g}}$ becomes positive and the LTM appeared. The large increase in the $R i_{\mathrm{g}}$ is related to a fast decrease of mechanical turbulence. Therefore, on these 3 days, LTMs were clearly observed with a large LTM intensity. On 25 and 30 June 2011 there was a less-pronounced increase of the $R i_{\mathrm{g}}$ values. These days have a smoother decrease of turbulence as well as a lower intensity of LTM.

As mentioned, Oke (1970) suggested a minimum $R i_{\mathrm{g}}$ threshold for LTM formation of $R i_{\mathrm{g}} \gtrsim 0.1$. During nighttime, when the main destabilizing force is mechanical turbulence, $R i_{\mathrm{g}}$ can be used to define the conditions for observing LTM. However, this $R i_{\mathrm{g}}$ threshold cannot be compared with our results because we observe an LTM when $\partial \overline{\theta_{\mathrm{v}}} / \partial z$ is changing at the surface. Therefore, we cannot define an exact threshold for LTM formation and we focus our analysis in the change of the increase rate of the $R i_{\mathrm{g}}$ values.

Decrease of mechanical turbulence during the afternoon transition can be also studied by using friction velocity $\left(u_{*}\right)$. Figure 6 shows the temporal evolution of $u_{*}$ at $2 \mathrm{~m}$ during the evening transition for all the studied days with a $5 \mathrm{~min}$ average. Due to the orography, during the afternoon, $u_{*}$ de-
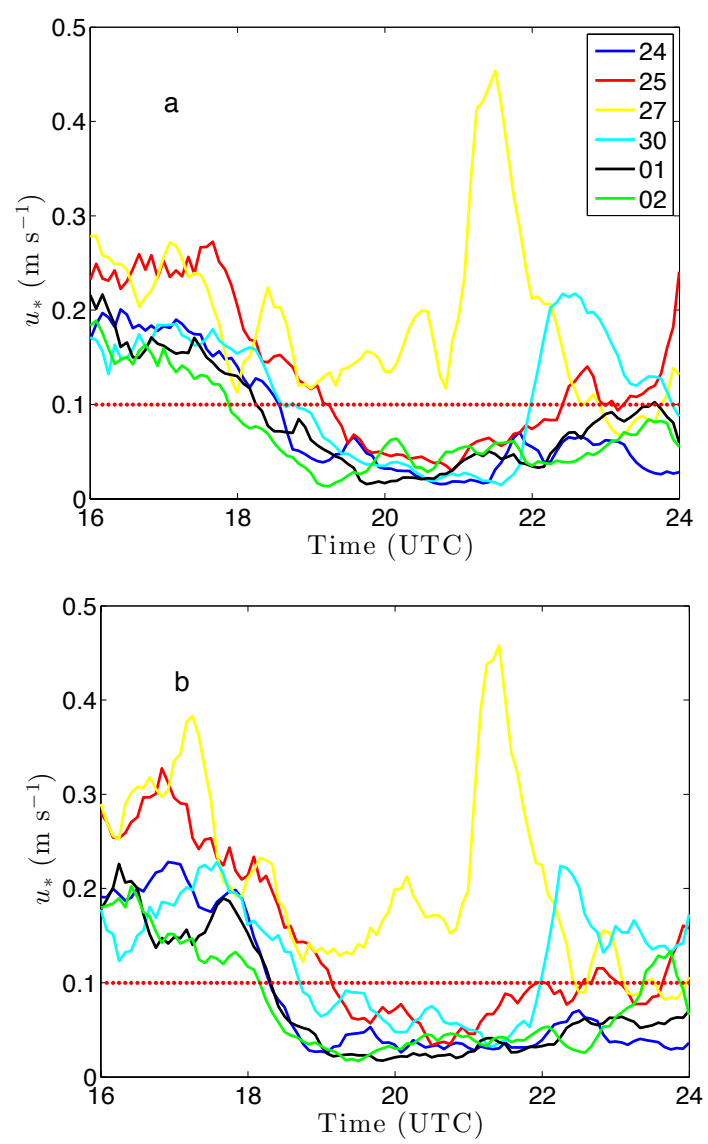

Figure 6. Temporal evolution of $u_{*}$ from 16:00 to 24:00 UTC on all the studied days at (a) T1 and (b) T2.

creased from around $0.25 \mathrm{~m} \mathrm{~s}^{-1}$ to values below $0.1 \mathrm{~m} \mathrm{~s}^{-1}$ (around 18:30 UTC at T1 and 18:00 UTC at T2). Afterwards it slightly increases but remains at lower values. Vasudeva Murthy et al. (2005) pointed out that an LTM can occur with friction velocities greater than about $0.1 \mathrm{~m} \mathrm{~s}^{-1}$, but the layer slowly fades away. In our study case, during most of the IOPs $u_{*}$ was reduced to values lower than $0.1 \mathrm{~m} \mathrm{~s}^{-1}$ shortly after the LTM occurrence except on 27 June 2011, when friction velocity clearly presented values higher than $0.1 \mathrm{~m} \mathrm{~s}^{-1}$ during the evening transition at both masts. Therefore, during this day turbulence prevented the appearance of an LTM. Moreover, on 30 June $2011 u_{*}$ had low values but only during a short period during which an LTM occurred (see Fig. 6a, b).

Mukund et al. (2010) used wind speed fluctuations to analyse turbulence and its influence on LTM occurrence. Figure 7 shows the horizontal wind speed measured at $20 \mathrm{~Hz}$ and its mean value (a $500 \mathrm{~s}$ moving average) for two different IOPs, 24 June and 27 June 2011, which represent the most extreme cases. The LTM occurrence on 24 June (see Table 1) is associated with a clear decrease not only of mean wind speed but also of wind speed fluctuations (see Fig. 7a). On the contrary, on 27 June, when an LTM is not observed, Fig. $7 b$ shows that neither mean wind speed nor turbulence intensity decrease 

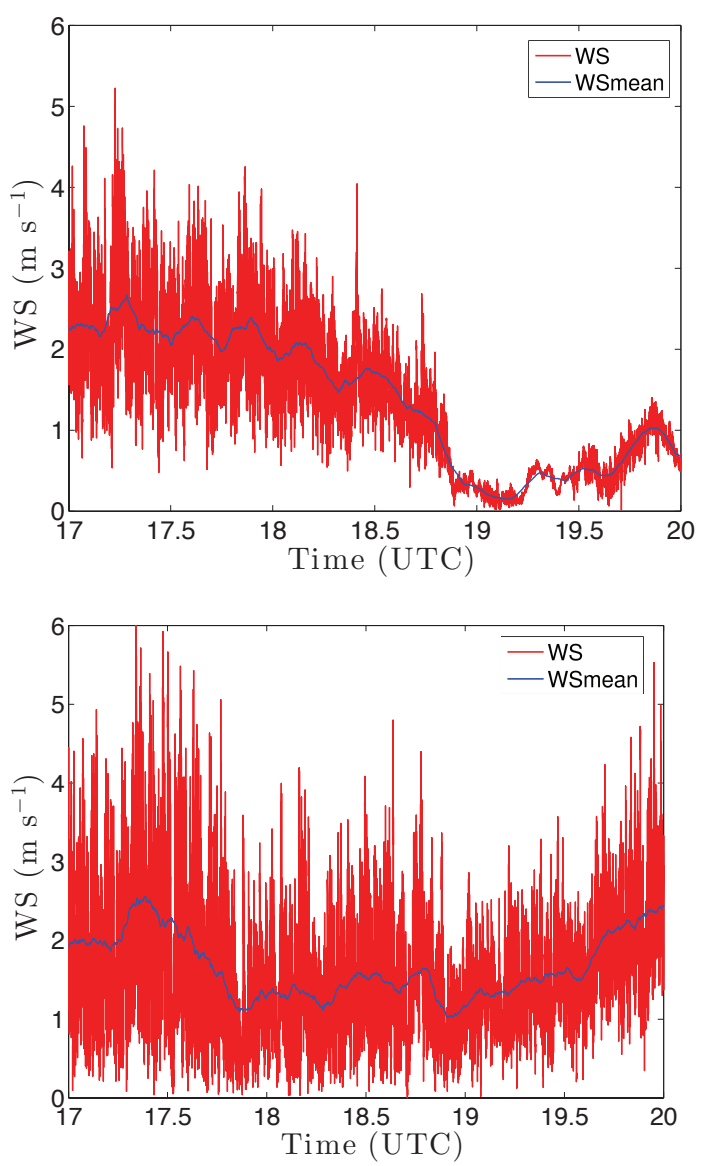

Figure 7. Temporal evolution of mean wind speed and deviation from mean wind speed on 24 (top) and 27 June 2011 (bottom).

during the evening transition. By comparing these facts with the parameters described in Table 1, we can directly relate turbulence and mean wind velocity with the intensity of the LTM. IOPs with a clear decrease on turbulence during the afternoon transition, such as 24 June and 1 or 2 July 2011, present larger LTM intensity. Those days with a lower or non-existing decrease of wind speed fluctuations have a lesspronounced LTM or no LTM present.

\subsection{Radiation}

Narasimha (1991), Vasudeva Murthy et al. (2005) and Mukund et al. (2010, 2014) pointed out the radiative origin of LTM. For this reason, we also analyse the radiation measurements taken by the radiometers located near T2. Unfortunately, during all the days of the campaign, a shadow produced by the $60 \mathrm{~m}$ tower located $160 \mathrm{~m}$ to the northwest of T2 affected the shortwave and net radiation measurements. Consequently, here we can only analyse the upwelling longwave radiation recorded by the Kipp \& Zonen CNR1 radiometer located at $0.8 \mathrm{~m}$. Additionally, we estimate longwave radiation at the LTM height by using the conservation of heat equation (Stull, 1988):

$$
\frac{\partial \bar{\theta}}{\partial t}+\overline{U_{j}} \frac{\partial \bar{\theta}}{\partial x_{j}}=v_{\theta} \frac{\partial^{2} \bar{\theta}}{\partial x_{j}^{2}}-\frac{1}{\bar{\rho} C_{p}} \frac{\partial Q^{*}}{\partial x_{j}}-\frac{L_{\mathrm{v}} E}{\bar{\rho} C_{p}}-\frac{\partial\left(\overline{u_{j}^{\prime} \theta^{\prime}}\right)}{\partial x_{j}},
$$

where $x_{j}$ represents $(x, y, z)$ for $j=(1,2,3), \bar{\theta}$ and $\theta^{\prime}$ are the mean and fluctuating components of the potential temperature, $v_{\theta}$ is the kinematic molecular diffusivity for heat in air, $Q^{*}$ is the net radiation, $L_{v}$ is the latent heat of vaporization of water, $E$ is the phase change rate, $\rho$ is density of the air, $C_{p}$ is the specific heat at constant pressure for moist air and $U_{j}$ and $u_{j}^{\prime}$ are the mean and fluctuations of the wind components $(u, v, w)$ for $j=(1,2,3)$.

The first term represents the tendency of the potential temperature. The second term describes the advection of heat by the mean wind. The third term is the mean molecular conduction of heat. The fourth term represents the net radiation flux divergence. The fifth term describes the latent heat release and the sixth term is the divergence of the turbulent heat flux. Despite that large values of latent heat were measured at noon during the BLLAST campaign, the fifth term of Eq. (5) is smaller when compared with the other terms. This term on 1 July 2011, for instance, was approximately $0.15 \mathrm{~K} \mathrm{~m} \mathrm{~s}^{-1}$ during daytime but decreased to values close to $0.01 \mathrm{~K} \mathrm{~m} \mathrm{~s}^{-1}$ during the evening transition.

If we consider very light winds, horizontal homogeneity and neglect subsidence, the heat equation can be written as

$$
\frac{\partial \bar{\theta}}{\partial t}=v_{\theta} \frac{\partial^{2} \bar{\theta}}{\partial z^{2}}-\frac{1}{\bar{\rho} C_{p}} \frac{\partial Q^{*}}{\partial z}-\frac{\partial\left(\overline{w^{\prime} \theta^{\prime}}\right)}{\partial z} .
$$

We integrate this equation from the ground to LTM height and average it every $5 \mathrm{~min}$. We obtain an approximation for the radiation at LTM height, which reads

$$
\left.\frac{Q^{*}}{\overline{\bar{\rho}} C_{p}}\right|_{z=\mathrm{LTM}}=-\left.v_{\theta} \frac{\partial \bar{\theta}}{\partial z}\right|_{z=0 \mathrm{~m}}+\left.\frac{Q^{*}}{\bar{\rho} C_{p}}\right|_{z=0 \mathrm{~m}}-\left.\overline{w^{\prime} \theta^{\prime}}\right|_{z=2 \mathrm{~m}} \text {. }
$$

It is important to note that the tendency of potential temperature vertically integrated from the surface to the LTM height is much smaller than the other terms and for this reason is neglected.

The second term of Eq. (7) is computed by using the temperature measured by the IR120 infrared surface temperature sensor and the lowest thermocouple located at $0.015 \mathrm{~m}$, and we approximate $v_{\theta}$ to the ground molecular diffusion value. Moreover, to estimate the heat flux we use the measurements at the lowest SAT, located at $2 \mathrm{~m}$, even though it is outside the integration domain. During evening transition, most of $\left.\frac{Q^{*}}{\bar{\rho} C_{p}}\right|_{z=0 \mathrm{~m}}$ and $\left.\frac{Q^{*}}{\bar{\rho} C_{p}}\right|_{z=\mathrm{LTM}}$ correspond to longwave radiation. Therefore, considering that the main contributor of the upwelling longwave radiation ( $\mathrm{Lu}$ ) is the ground, we compute the longwave radiation emitted at the ground using the ground temperature $\left(T_{\mathrm{g}}\right)$ measured by the IR 120 infrared sur- 

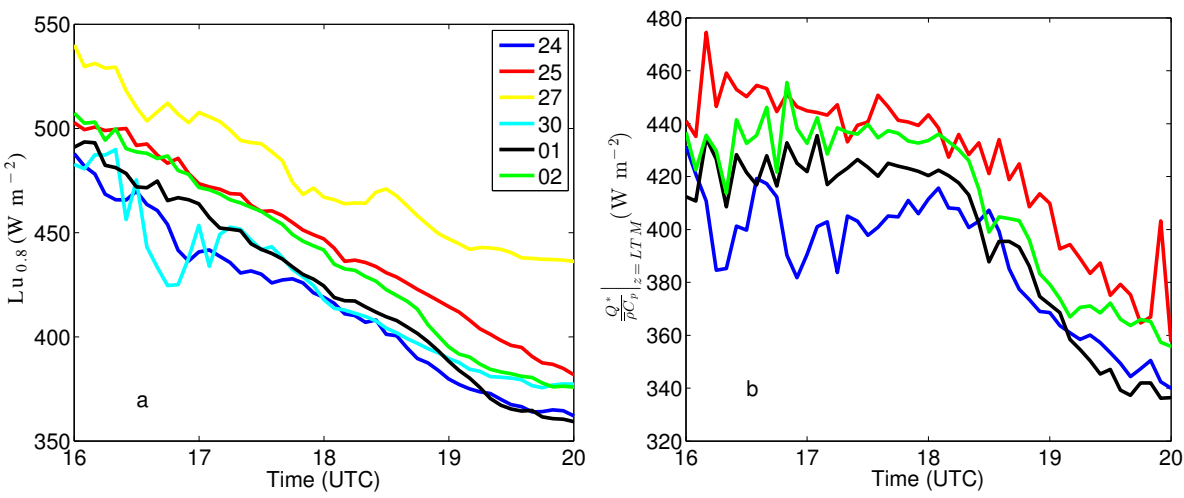

Figure 8. Temporal evolution of upwards longwave radiation (Lu) (a) measured at $0.8 \mathrm{~m}$ on 24, 25, 27 and 30 June 2011 and 1 and 2 July 2011 and (b) estimated, by using Eq. (7), at LTM height on 24 and 25 June 2011 and 1 and 2 July 2011 using Eq. (7).

face temperature sensor as

$$
\left.\left.\frac{Q^{*}}{\bar{\rho} C_{p}}\right|_{z=0 \mathrm{~m}} \simeq \mathrm{Lu}\right|_{z=0}=\varepsilon \sigma_{\mathrm{b}} T_{\mathrm{g}}^{4},
$$

where $\varepsilon$ is the emissivity of the ground (0.986) and $\sigma_{\mathrm{b}}$ is the Stefan-Boltzmann constant.

To discard LTM produced by variations of the ground characteristics during the LTM period, we analysed the evolution of ground emissivity by using the measurements of longwave radiation at $0.8 \mathrm{~m}$ and temperature at $0.015 \mathrm{~m}$. The results do not shown any particular modification during the occurrence of LTM. Moreover, a sensitivity study changing the value prescribed of the surface emissivity (Gayevsky, 1952; Arya, 2001) has been also performed without qualitatively modifying the results presented below.

Figure 8a shows the temporal evolution of the upwelling longwave radiation measured by the Kipp \& Zonen CNR1 net radiometer at $0.8 \mathrm{~m}$. During the afternoon transition, we observe a nearly constant decay rate for the upwelling longwave radiation at $0.8 \mathrm{~m}$. Longwave radiation at the ground calculated by using Eq. (8) presents a similar evolution (not shown). However, we cannot correlate these two upwelling longwave radiations to analyse if there is any difference to explain the appearance of the LTM because the IR120 infrared surface temperature sensor and the longwave net radiation sensor have different response times $(<1 \mathrm{~s}$ for the IR120 infrared camera and $18 \mathrm{~s}$ for the Kipp \& Zonen CNR1 net radiometer). Moreover, both sensors were not sampling using the same data logger. Consequently, we focus on analysing the differences in the decay rate of upwelling longwave radiation at $0.8 \mathrm{~m}$ and the longwave radiation at LTM height calculated by using Eq. (7).

Figure $8 \mathrm{~b}$ shows the temporal evolution of the longwave radiation at the LTM height estimated by using Eq. (7). This figure does not include the longwave radiation at the LTM height for 27 and 30 June 2011 because of some problems occurred with the IR surface temperature sensor measurements during these IOPs. In contrast to Fig. 8a, the longwave radi- ation decay rate is not constant and increases around 17:3018:30 UTC, when the LTM appears for some IOPs. This increase in the longwave radiation decay rate can lead to a more rapid local decrease in air temperature and the formation of an LTM.

It is important to note that with the deployed instruments during the campaign, we are not able to study the vertical profile of the air emissivity. We use longwave radiation measured at $0.8 \mathrm{~m}$ and the closest measurements of temperature ( $2 \mathrm{~m}$ ) to estimate air emissivity, and no variation of the air emissivity occurred around the time of the LTM for any of the analysed days (not shown).

Mukund et al. (2010) reported that LTM intensity decreases when clouds were present, also suggesting the importance of radiation in the phenomenon. By analysing the ceilometer measurements obtained during BLLAST (not shown), a completely clear sky is reported for all the IOP evening transitions except on 30 June 2011. From the previous section, we know that during this day even though the conditions of turbulence were acceptable to observe LTM and LTM presented similar values to other IOPs, there was a combination of low intensity and short duration not present in other IOPs. These LTM characteristics can be also caused by the presence of clouds.

\section{Conclusions}

The presence of a lifted temperature minimum during the evening transition is studied by means of observations taken during the BLLAST campaign. The campaign site presented ground characteristics suitable for observing LTM with large ground emissivity and thermal inertia. During this period of the day, LTMs were observed at different heights and with different intensity and duration during all IOPs except on 27 June 2011.

With the instrumentation deployed during the campaign we were not able to verify all the previous hypotheses to explain the appearance of LTM. For instance, the presence of 
aerosols at lower height were not monitored during the campaign.

Additionally, it would be difficult to analyse, by using observations, the budget between radiation warming and turbulence cooling during the evening transition. While small Kaijo-Denki sonics could be used at 15 and $30 \mathrm{~cm}$ to measure cooling via sensible heat flux divergence, radiation measurements would be much more difficult at those heights close to the surface, and not possible with commercial pyranometers.

Moreover, it is important to note that the research study focusses on the afternoon transition. To our knowledge, the heat budget (the competition between turbulent fluxes and radiation divergence) at the different levels close to the surface has not been studied during this period of the day. In fact, the current MATERHORN observational campaign (Jeglum et al., 2013) was partially designed to study the evolution of the heat budget during the afternoon/evening transition.

By studying the wind conditions characterized by a mountain-plain flow, we conclude that the days with a more marked decrease of mean wind speed and wind speed fluctuations (24 June or 1 July 2011) have a more intense LTM. On the other hand, on the days without a reduction of wind speed, such as 27 June 2011, LTM cannot be observed during the evening transition.

Analysing $R i_{\mathrm{g}}$ during the evening transition, we observe that the LTM is detected on days with a faster increase of $R i_{\mathrm{g}}$, i.e., a faster decrease of mechanical turbulence. However, due to the fact that $\partial \overline{\theta_{\mathrm{v}}} / \partial z$ is changing sign during the evening transition, no threshold of $R i_{\mathrm{g}}(\mathrm{Oke}, 1970)$ can be defined.

Finally, the longwave-radiative conditions are analysed. We study the differences in the decay rate of the upwelling longwave radiation at $0.8 \mathrm{~m}$ and the longwave radiation at LTM height. Longwave radiation at LTM height decays at two different rates in contrast to the upwelling longwave radiation decay at $0.8 \mathrm{~m}$ which is constant in time. This change in the radiative conditions can modify the temporal evolution of the potential temperature creating the LTM.

To conclude, during evening transition it is possible to observe the lifted temperature minimum over a terrain with moderate/large emissivity and thermal inertia. In this study case, really calm conditions were observed during evening transition due to the presence of the Pyrenees which produces an early evening calm period easily defined through a change in the wind velocity and turbulence. Moreover, a change in the radiative conditions was observed during an LTM period which confirms its radiative origin.

Acknowledgements. This project was performed under the Spanish MINECO projects CGL2009-08609, and CGL2012-37416-C04-03. The MODEM radio sounding station and the UHF wind profiler have been supported by CNRS, Université Paul Sabatier and the FEDER program (contract no. \#34172 Development of the instrumentation of Observatoire Midi-Pirénées-PIRENEA-ESPOIR). The $60 \mathrm{~m}$ tower equipment has been supported by CNRS, Université
Paul Sabatier and the European POCTEFA 720 FluxPyr program. One EC station was supported by Wageningen University and two EC stations were supported by the University of Bonn and DFG project SCHU2350/21.

The BLLAST field experiment was made possible thanks to the contribution of several institutions and support: INSU-CNRS (Institut National des Sciences de l'Univers, Centre National de la Recherche Scientifique, LEFE-IDAO program), Météo-France, Observatoire Midi-Pirénées (University of Toulouse), EUFAR (EUropean Facility for Airborne Research) and COST ES0802 (European Cooperation in Science and Technology). The field experiment would not have occurred without the contribution of all participating European and American research groups, which all have contributed in a significant amount. The BLLAST field experiment was hosted by the instrumented site of Centre de Recherches Atmosphériques, Lannemezan, France (Observatoire Midi-Pirénées, Laboratoire d'Aérologie). The BLLAST data are managed by SEDOO, from Observatoire Midi-Pirénées. This work was partially supported through funding from the U.S. Office of Naval Research award \#N00014-11-1-0709, Mountain Terrain Atmospheric Modeling and Observations (MATERHORN) Program.

Finally, we would like to thank K. R. Sreenivas from the Jawaharlal Nehru Centre for Advanced Scientific Research and S. Wacker from the Physikalisch-Meteorologisches Observaturium Davos for fruitful discussions about atmospheric radiation.

Edited by: S. Galmarini

\section{References}

Arya, S. P.: Introduction to Micrometeorology, Academic Press, San Diego, USA. 420 pp., 2001.

Bhat, G. S.: Near-surface temperature inversion over the Arabian Sea due to natural aerosols, Geophys. Res. Lett., 33, L02802, doi:10.1029/2005GL024157, 2006.

Campbell, G. C.: Measurement of air temperature fluctuations with thermocouples, Atmospheric Sciences Laboratory, White Sands Missile Range, ECOM-5273, 10 pp., 1969.

Campbell, G. S. and Norman, J. (Eds.): An Introduction to Enviromental Biophysics, Springer, 2 Edn., 1998.

De Coster, O. M. Y. and Pietersen, H. P.: BLLAST-uniform processing of Eddy-Covariance data, Internship Report Meteorology and Climatology, Wageningen University and Research Center, the Netherlands, 30 pp., available at: http://bllast.sedoo.fr/documents/reports/H-Pietersen_ O-de-Coster_BLLAST-surf_flx-uniform-processing.pdf, 2011.

Edwards, J. M.: Radiative Processes in the Stable Boundary Layer: Part I. Radiative Aspects, Bound.-Lay. Meteorol., 131, 105-126, 2009a.

Edwards, J. M.: Radiative processes in the stable boundary layer: Part II. The development of the nocturnal boundary layer, Bound.-Lay. Meteorol., 131, 127-146, 2009b.

Gayevsky, U. L.: Surface temperature of large territories, Proc. Main Geophys. Obs., 26, 291-310, 1952.

Geiger, R. (Ed.): The Climate Near the Ground, Harvard University Press, 1957.

Jeglum, M. E., Fernando, H. J. S., Pardyjak, E. R., Zajic, D., De Wekker, S. F. J., Pace, J. C., Di Sabatino, S., Hoch, S. W., Steen- 
burgh, J.Pu, Z., Whiteman, C. D., Massey, J. D., Wang, Y., Leo, L. S. , Hocut, C. M., Zhang, H., and Jensen, D.: The Mountain Terrain Atmospheric Modeling and Observations (MATERHORN) Program: Observations and Results, 15th Conference on Mesoscale Processes (6-9 August 2013), Portland, OR, USA, 2013

Lake, J. V.: The temperature profile above bare soil on clear nights, Q. J. Roy. Meteor. Soc., 82, 187-197, 1956.

Lothon, M., Lohou, F., Pino, D., Couvreux, F., Pardyjak, E. R., Reuder, J., Vilà-Guerau de Arellano, J., Durand, P, Hartogensis, O., Legain, D., Augustin, P., Gioli, B., Lenschow, D. H., Faloona, I., Yagüe, C., Alexander, D. C., Angevine, W. M., Bargain, E, Barrié, J., Bazile, E., Bezombes, Y., Blay-Carreras, E., van de Boer, A., Boichard, J. L., Bourdon, A., Butet, A., Campistron, B., de Coster, O., Cuxart, J., Dabas, A., Darbieu, C., Deboudt, K., Delbarre, H., Derrien, S., Flament, P., Fourmentin, M., Garai, A., Gibert, F., Graf, A., Groebner, J., Guichard, F., Jiménez, M. A., Jonassen, M., van den Kroonenberg, A., Magliulo, V., Martin, S., Martinez, D., Mastrorillo, L., Moene, A. F., Molinos, F., Moulin, E., Pietersen, H. P., Piguet, B., Pique, E., RománCascón, C., Rufin-Soler, C., Saïd, F., Sastre-Marugán, M., Seity, Y., Steeneveld, G. J., Toscano, P., Traullé, O., Tzanos, D., Wacker, S., Wildmann, N., and Zaldei, A.: The BLLAST field experiment: Boundary-Layer Late Afternoon and Sunset Turbulence, Atmos. Chem. Phys., 14, 10931-10960, doi:10.5194/acp14-10931-2014, 2014.

Mukund, V., Ponnulakshmi, V. K., Singh, D. K., Subramanian, G., Sreenivas, K. R.: Hyper-cooling in the nocturnal boundary layer: the Ramdas paradox, Phys. Scripta, 142, 014041, 2010.

Mukund, V., Singh, D. K., Ponnulakshmi, V. K., Subramanian, G., and Sreenivas, K. R.: Field and laboratory experiments on aerosol-induced cooling in the nocturnal boundary layer, Q. J. Roy. Meteor. Soc., 140, 151-169, doi:10.1002/qj.2113, 2014.

Nadeau, D. F., Pardyjak, E. R., Higgins, C. W., Huwald, H., and Parlange, M. B.: Flow during the evening transition over steep Alpine slopes, Q. J. Roy. Meteor. Soc., 139, 607-624, 2013.

Narasimha, R.: When and why air can be cooler than ground just below: A theory for the Ramdas effect, J. Indran. Inst. Sci., 71, 475-483, 1991.

Narasimha, R.: The dynamics of the Ramdas layer, Curr. Sci. India, 66, 16-23, 1994.
Narasimha, R. and Vasudeva Murthy, A. S.: The energy balance in the Ramdas layer, Bound.-Lay. Meteorol., 76, 307-321, 1995.

Oke, T. R.: The temperature profile near the ground on calm clear nights, Q. J. Roy. Meteor. Soc., 96, 14-23, 1970.

Ponnulakshmi, V. K., Mukund, V., Singh, D. K., Sreenivas, K. R., and Subramanian, G.: Hypercooling in the Nocturnal Boundary Layer: Broadband Emissivity Schemes, J. Atmos. Sci., 69, 28922905, 2012.

Ramdas, L. A. and Atmanathan, S.: The vertical distribution of air temperature near the ground at night, Beitr. Geophys., 37, 116$117,1932$.

Ramdas, L. A. and Atmanathan, S.: Über das nächtliche temperaturminimum über nackten boden in Poona, Meteorol. Rundsch., 10, 1-11, 1957.

Savijärvi, H.: Radiative and turbulent heating rates in the clear-air boundary layer, Q. J. Roy. Meteor. Soc., 132, 147-161, 2006.

Savijärvi, H.: High-resolution simulations of the night-time stable boundary layer over snow, Q. J. Roy. Meteor. Soc., 140, 11211128, 2014.

Skamarock, W., Klemp, J. B., Dudhia, J., Gill, D. O., Barker, D., Duda, M. G., Huang, X.-Y., and Wang, W.: A description of the advanced research WRF version 3, Tech. Rep., 870, NCAR/TN475+STR, NCAR. 2008.

Stull, R. B. (Ed.): An Introduction to Boundary Layer Meteorology, Kluwer Academic Publisher, Dordrecht, the Netherlands, 1988.

Sun, J., Burns, S. P., Delany, A. C., Oncley, S. P., Horst, T. W., and Lenschow, D. H.: Heat balance in the nocturnal boundary layer during CASES-99. J. Appl. Meteorol., 42, 1649-1666, 2003.

Vasudeva Murthy, A. S., Srinivasan, J., and Narasimha, R.: Theory of the lifted temperature minimum on calm clear nights, Philos T. R. Soc. A, 344, 183-206, 1993.

Vasudeva Murthy, A. S., Narasimha, R., and Varghese, S.: An asymptotic analysis of a simple model for the structure and dynamics of the Ramdas layer, Pure Appl. Geophys., 162, 18311857, 2005.

Whiteman, C. D.: Mountain meteorology: fundamentals and applications, Oxford University Press, Oxford, England, 2000.

Zdunkowski, W.: The nocturnal temperature minimum above the ground, Beitr. Phys. Atmos., 39, 247-253, 1966. 